\title{
Development of Biodegradable Food Packaging Materials from Agricultural Biomass
}

\author{
Jerome M Bidu ${ }^{1}$, Arnold Towo ${ }^{2}$, Liberato Haule ${ }^{1}$, Joshua C William ${ }^{1,3}$ and Lilian D \\ Kaale $^{3^{*}}$ \\ ${ }^{1}$ Department of Mechanical and Industrial Engineering, University of Dar es Salaam, P.O Box \\ 35131, Dar es Salaam, Tanzania. \\ ${ }^{2}$ Department of Agricultural Engineering, University of Dar es Salaam, P.O. Box 35134, Dar \\ es Salaam, Tanzania. \\ ${ }^{3}$ Department of Food Science and Technology, University of Dar es Salaam, P.O. Box 35134, \\ Dar es Salaam, Tanzania. \\ Emailaddresses: jeromebidu@gmail.com,towoarn@gmail.com,liberatohaule@yahoo.co.uk, \\ joshuabavuma30@gmail.com,elykaale@gmail.com* ; elykaale@yahoo.com* \\ *Corresponding author'
}

Received 16 Jul 2021, Revised 16 Oct 2021, Accepted 23 Oct 2021, Published Dec 2021

DOI: https://dx.doi.org/10.4314/tjs.v47i5.6

\begin{abstract}
This study utilised maize husk fibres and pulp to prepare a biocomposite fabric for food packaging. The optimum conditions for extracting maize husk fibres were determined experimentally to be $5 \mathrm{~g} / \mathrm{l}$ of sodium hydroxide concentration at $100{ }^{\circ} \mathrm{C}$ for 60 minutes and liquor ratio of 1:20. The fabric was manufactured by solution casting of maize husk pulp on a web prepared by aligning maize husk and sisal fibres using a deckle and frame. The sisal fibre content was varied from 5 to $50 \%$ at ratios ranging from 95:5 to 50:50 (maize: sisal fibres). The biodegradable fabric was characterised using three mechanical properties: tear strength, tensile strength, and abrasion resistance. The tear strength ranged from 0.79 MPa to 3.93 MPa whereas the tensile strength ranged from 13.35 MPa to $56.46 \mathrm{MPa}$, which conforms to the data available from literature. Abrasion tests verified that there was no mass loss at 5,000, 10,000 and 15,000 cycles. Overall, the study findings show that maize husk fibres can replace up to $80 \%$ of sisal fibres in materials for food packaging applications without compromising their quality.
\end{abstract}

Keywords: Maize husk fibre, biocomposite, sisal fibres, food packaging.

\section{Introduction}

Food security has continued to be a high priority issue on the development agenda in developing countries. Although substantial progress has been made in sustaining Africa's historical high gross domestic product (GDP) growth rate for the past decade, bottlenecks persist in improving the agricultural sector growth and share in the total GDP, and in reducing susceptibility to frequent food crises and famines along the value chain. These need to be addressed before African countries can become food secure. Particularly, the regional agriculture sector contends with multiple challenges such as insufficient diversification into higher value-added marketable products, sufficient long shelf-life, wastage, and post-harvest losses. Postharvest losses at almost every stage of the food chain may be reduced by using appropriate packaging. Packaging is an essential part of a long-term incremental development process aimed to reduce losses, that will have to employ a blend of technologies and processes (Wohner et al. 2019). 
Packaging is pivotal in containing and protecting food as it progresses from the producer to the end user through the supply chain (Johansson et al. 2012, Opara and Mditshwa 2013, Bhardwaj et al. 2020). However, not all packaging materials are favourable for food packaging. These nonfavourable packaging materials include those made from petroleum-based materials, which have negative effects on both health and the environment. Paradoxically, petroleum-based food packaging materials have become abundant in recent decades despite increasingly being recognised as real and growing environmental pollutants due to their non-biodegradable nature (Franz and Welle 2003, Halonen et al. 2020). This has resulted in growing academic research, further driven by commercial demand for biodegradable and economically viable food packaging materials, often involving rediscovery or repurposing of natural and/or renewable textile fibres and materials (Johansson et al. 2012).

Moreover, a $50 \%$ increase in global food supplies would be required by 2050 due to the increase in global population growth, hence more demand for food packaging. Thus, there is a need to produce locally-available, environmentally-friendly (biodegradable) food packaging materials and extend the shelf-life of the foods (Johansson et al. 2012, Makhijani et al. 2015). Various biodegradable food packaging materials are producible by processing agricultural biomass, e.g., cassava peels, avocado seeds, maize husks, wheat straw, rice straw, and banana peels (Mostafa et al. 2018, Chander 2019). Biodegradable polymers are of crucial interest to a variety of fields such as food packaging (Mooney 2009, Mostafa et al. 2018). They can replace petroleum-based polymers, thus reducing the problem of disposability of traditional food packaging materials (Dungani et al. 2016, Folino et al. 2020, Zikmanis et al. 2020). To produce environmentally-friendly, renewable and biodegradable food packaging materials, the investigation of polymers has been carried out in different fields (Ibrahim et al. 2018, Yang et al. 2019). Biopolymer films, which contain polysaccharide ingredients, have been used to produce edible films with good mechanical and water barrier properties, and are viable solutions for environmental sustainability (Briassoulis 2006, Accinelli et al. 2012, Koch and Mihalyi 2018, Folino et al. 2020).

Cellulose, a carbohydrate polymer made up of tens to hundreds to several thousand monosaccharide units, provides the main building blocks for plant fibres. It is a natural homopolymer composed of D-glucopyranose units, which are linked together by $\alpha-(1 \rightarrow 4)$ glycosidic bonds (Klemm et al. 2009, Lavanya et al. 2011, Huq et al. 2012). It is a sustainable raw material that has gained interest as a renewable, environmentallyfriendly, and cost-effective reinforcing agent for composite materials (Samir et al. 2005, Huq et al. 2012, Wulandari et al. 2016). Few studies have been carried out on the usability of maize husks for extraction of fibres for textile and food applications (Maity et al. 2012, Jain et al. 2017). Practical use of maize husk fibres for food packaging applications could become a major discovery in this direction (Salam et al. 2007, Jain et al. 2017).

The technique of extracting natural fibres from plant stems and other agricultural biomass involves decomposition of pectin, which binds the fibres to the woody inner core of plant materials (Lee et al. 2020a). The process employs water for microbial or chemical action to separate fibres from the woody core, i.e., the xylem, and surrounding the epidermis as well (Ebisike 2013). The aim of this research was to develop a biodegradable food packaging material based on maize husk fibres.

\section{Methodology \\ Materials and chemicals}

To prepare biocomposite sheets, the researchers used the following materials and chemicals: Maize husks and sisal fibres collected from Tandale market and $21^{\text {st }}$ Century Holdings Ltd (MeTL) Chang'ombe, respectively, in Dar es Salaam, Tanzania. Analytical grade reagents used were sodium hydroxide and acetic acid from SigmaAldrich. Distilled water was obtained from the Department of Chemical and Process Engineering-University of Dar es Salaam. 
Other consumables used were aluminium foil, and plastic packaging.

\section{Equipment and apparatus}

An ES-2255 Europe blender, a Mathis Labomat BFA-12 infrared beaker dyeing machine, Wintech analytical balance-JA203P, drier box Zuk-OV23, Vgotech Martindale230GFKh abrasion tester, and Griefchem 791 magnetic stirrer with hot plate were used. All these equipment and apparatus were in the Textile Laboratory at the University of Dar es Salaam. An SDLATLAS Power Tear Elmendorf M008HE tester and Instron Series IX automated materials testing system 8.25.00 Machine were accessed from the Tanzania Bureau of Standards (TBS).

\section{Preparation of fibres from maize husks}

The maize husks were obtained from raw maize, Figure 1 (a), washed, and rinsed thoroughly with water to remove surface impurities. The husks were dried in an oven at $90{ }^{\circ} \mathrm{C}$ for 45 minutes, Figure 1 (b), prior to fibre extraction. Sodium hydroxide at concentrations of $3 \mathrm{~g} / \mathrm{l}, 4 \mathrm{~g} / \mathrm{l}$ and $5 \mathrm{~g} / \mathrm{l}$ were used for degumming and releasing fibres from the maize husks. The material liquor ratio used was 1:20. In this regard, $10 \mathrm{~g}$ of dried maize husks were dipped into a beaker containing $200 \mathrm{~mL}$ of sodium hydroxide solution, which was then mounted onto the infrared beaker dyeing machine.

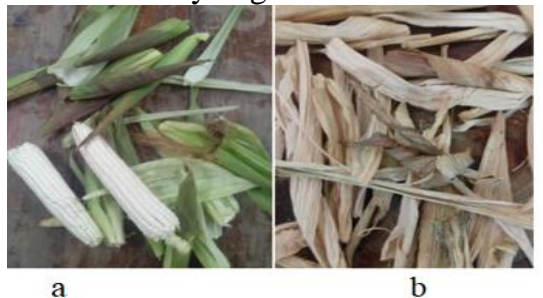

Figure 1: Maize husks (a) green (b) dried.

The conditions and procedures for extracting fibres were adapted from Kambli et al. (2016). The extraction time varied from 40 $\mathrm{min}, 60 \mathrm{~min}$, and $80 \mathrm{~min}$ and temperatures of
60, 80 and $100{ }^{\circ} \mathrm{C}$. The extracted fibres, Figure 2 (a), were rinsed thoroughly in water to remove lignin, hemicellulose and any remaining sodium hydroxide in accordance with the procedures explained by Kambli et al. (2016). The extracted fibres were neutralised with dilute acetic acid $0.1 \%(\mathrm{w} / \mathrm{v})$, rinsed three times with distilled water and, finally dried in an oven at $70{ }^{\circ} \mathrm{C}$ for 45 minutes. Figure 2 (b) shows fibres that were extracted from maize husks using $5 \mathrm{~g} / \mathrm{l}$ of $\mathrm{NaOH}$ solution at $100{ }^{\circ} \mathrm{C}$ for 60 minutes with no acid treatment and with acid treatment.

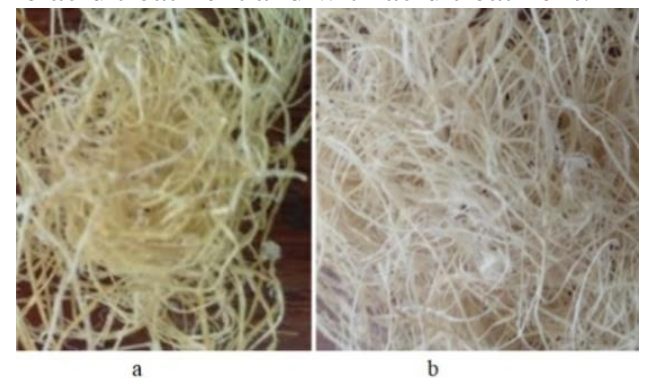

Figure 2:Fibres from maize husks extracted with $5 \mathrm{~g} / \mathrm{l}$ of $\mathrm{NaOH}$ solution at $100{ }^{\circ} \mathrm{C}$ for 60 minutes (a) no acid treatment (b) treated with acid.

\section{Preparation of maize husk pulp by delignification}

Pulp was formed by taking $15 \mathrm{~g}$ of the maize husks and dipping them in a $200 \mathrm{~mL}$ beaker filled with $150 \mathrm{~mL}$ of $10 \% \mathrm{w} / \mathrm{v} \mathrm{NaOH}$ solution ( $\mathrm{Li}$ et al. 2013). The mixture was heated for one hour at a temperature of $90{ }^{\circ} \mathrm{C}$ to remove the lignin, hemicellulose, and other pectin substances (Vardhini et al. 2016). After heating, the mixture was filtered and rinsed twice in water to separate the insoluble pulp and remove excess $\mathrm{NaOH}$. The rinsed pulp was blended using an ES-2255 blender at $3,000 \mathrm{rpm}$ for 5 minutes. The process flow diagram for maize pulp formation is illustrated in Figure 3.

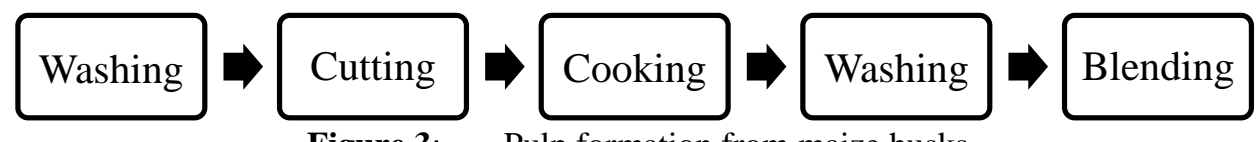

Figure 3: Pulp formation from maize husks. 


\section{Web formation}

The web was formed using $35 \mathrm{~g}$ of a previously prepared solution of maize husk pulp. The solution was spread onto a mould and deckle to form a web by allowing the water to pass through the mesh leaving the pulp on the deckle. Different proportions of maize husk fibres and sisal fibres were aligned on top of the formed web. Another 15 $\mathrm{g}$ of maize husks pulp were spread onto the top of the aligned fibres followed by pressing to produce the biocomposite as presented in the process flow diagram in Figure 4.

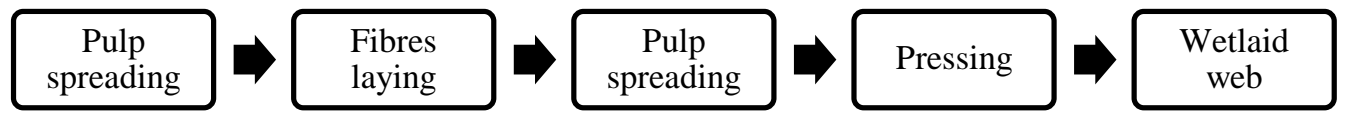

Figure 4: Web formation process flow diagram.

Table 1 shows different ratios between maize and sisal fibres to establish an optimum amount of maize fibres which can be used to replace sisal fibres.

Table 1: Proportion of maize and sisal fibres in fabrics

\begin{tabular}{|c|c|c|}
\hline $\begin{array}{l}\text { Sample } \\
\text { type }\end{array}$ & Code & $\begin{array}{l}\text { Maize husks sample } \\
\text { description \% }\end{array}$ \\
\hline Maize pulp & MFSF1 & 100:0 \\
\hline $\begin{array}{l}\text { Maize: } \\
\text { Sisal }\end{array}$ & MFSF2 & $95: 5$ \\
\hline $\begin{array}{l}\text { Maize: } \\
\text { Sisal }\end{array}$ & MFSF3 & $90: 10$ \\
\hline $\begin{array}{l}\text { Maize: } \\
\text { Sisal }\end{array}$ & MFSF4 & $80: 20$ \\
\hline $\begin{array}{l}\text { Maize: } \\
\text { Sisal }\end{array}$ & MFSF5 & $70: 30$ \\
\hline $\begin{array}{l}\text { Maize: } \\
\text { Sisal }\end{array}$ & MFSF6 & $60: 40$ \\
\hline $\begin{array}{l}\text { Maize: } \\
\text { Sisal }\end{array}$ & MFSF7 & $50: 50$ \\
\hline $\begin{array}{l}\text { Maize: } \\
\text { Sisal }\end{array}$ & MFSF8 & $0: 100$ \\
\hline
\end{tabular}

\section{Tearing strength}

A SDLATLAS Power Tear Elmendorf M008HE tester was used to test the tearing strength of the biocomposite materials in accordance with the test method provided by ASTM D5734. Five fabric samples of rectangular size of $63 \mathrm{~mm} \times 76 \mathrm{~mm}$ were cut and prepared for determination of tear strength. The forces required to tear the fabric samples were recorded in terms of Newtons (N).

\section{Tensile strength measurements}

The test was conducted using an Instron Universal Testing Machine, Series IX Automated Materials Testing System 8.25.00 (Including: specimen preparation, preconditioning chamber at $25^{\circ} \mathrm{C} \pm 2$ and $55 \%$ $\mathrm{RH})$. Samples were cut to dimensions of 100 $\times 50 \times 1.5 \mathrm{~mm}$ (length $\times$ width $\times$ thickness) before placing them onto the sample holder. The data were analysed using $\mathrm{R}$ project software-version 4.0.5. The sequence of procedures was conducted according to ASTM D 3500.

\section{Abrasion resistance \\ Abrasion is the loss of performance characteristics, such as strength and appearance of the fabric which is related to serviceability of the material. ISO 12947-1- 1998 Textiles-determination of the abrasion resistance of fabrics by the Martindale Method - Part 1: Martindale abrasion testing apparatus (Brand: SDL Atlas) was used in this experiment. Five fabric samples, each with a diameter of $38 \mathrm{~mm}$, were used in the abrasion test.}

\section{Results and Discussion \\ Fibres extracted at different conditions}

Prior to extracting fibres from maize husks, the recipe was first optimised by considering the properties of maize husk fibres. These properties were whiteness, and yellowness indices. Yilmaz (2013) classified maize husk fibres extracted by varying sodium hydroxide $(\mathrm{NaOH})$ concentration, treatment time, and boiling temperature based on whiteness and yellowness indices. 
Figure 5(a) shows fibres obtained after treating maize husks with $3 \mathrm{~g} / \mathrm{l}$ of $\mathrm{NaOH}$ concentration for 60 minutes at a temperature of $140{ }^{\circ} \mathrm{C}$. The fibres are coarse, slender, and reddish brown in colour. Figure 5(b) shows fibres obtained after treating maize husks with $3 \mathrm{~g} / \mathrm{l}$ of $\mathrm{NaOH}$ concentration for 60 minutes at a temperature of $120{ }^{\circ} \mathrm{C}$. The maize husks were not fully disintegrated to release fibres and remained in bundles which were yellowish in colour and inflexible. The colour changed from yellowish to brownish at 120 ${ }^{\circ} \mathrm{C}$ and $140{ }^{\circ} \mathrm{C}$, respectively, due to the formation of low molecular carbohydrate and nitrogen compounds that migrate towards the surface and form a brown reaction product (Genco et al. 2011). Some of the husks remained intact probably due to variation in the quality of their inner and outer layers or lower and upper portions. At the $100{ }^{\circ} \mathrm{C}$ boiling temperature, complete disintegration of the maize husks was evident with resultant fibres yellowish in colour. This result is similar to what Reddy and Yang (2005) reported when they extracted fibres from maize husks using the boiling method.

Figure 5(c) shows fibres obtained after treating maize husks with $4 \mathrm{~g} / \mathrm{l}$ of $\mathrm{NaOH}$ concentration for 40 minutes at a temperature of $100{ }^{\circ} \mathrm{C}$. A similar result is observable in Figure $5(\mathrm{c})$, as disintegration of the maize

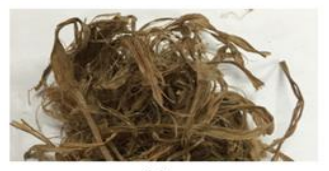

(a)

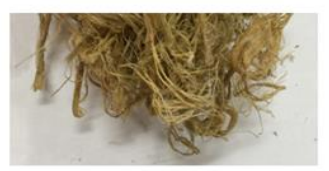

(c) husks was not enough to release fibres. Figure 5(d) shows fibres obtained after treating maize husks with $5 \mathrm{~g} / \mathrm{l}$ of $\mathrm{NaOH}$ concentration for 60 minutes at a temperature of $100{ }^{\circ} \mathrm{C}$. There was complete disintegration of the maize husks and the fibres obtained were very smooth, slender and yellowish in colour. Based on the observations of the extracted fibres, extraction of maize husk fibres using $5 \mathrm{~g} / \mathrm{l}$ of $\mathrm{NaOH}$ at $100{ }^{\circ} \mathrm{C}$ for 60 minutes was considered optimum.

\section{Formation of biocomposite}

The optimum conditions for biocomposite formation from maize husk pulp were established by considering the appearance, surface smoothness, compactness and flexibility as reported by Marichelvam et al. (2019). Biocomposites were formed by varying the proportions of sisal and maize husk fibres. The resulting biocomposites with different proportions of sisal and maize husk fibres differ in compactness, smoothness, and flexibility. Figure 6(a) shows the biocomposite formed with $20 \mathrm{~mL}$ of maize husk pulp mixed with $10 \mathrm{~g}$ of maize husks fibres. Figure 6(b) shows the biocomposite formed with $24 \mathrm{~mL}$ maize husk pulp and a ratio of 50:50 sisal fibres and maize husk fibres aligned into the formed web.

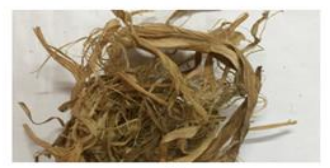

(b)

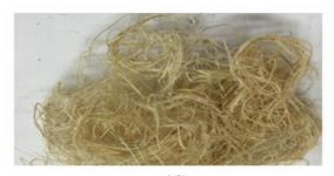

(d)

Figure 5: Maize husks fibres extracted under different conditions.
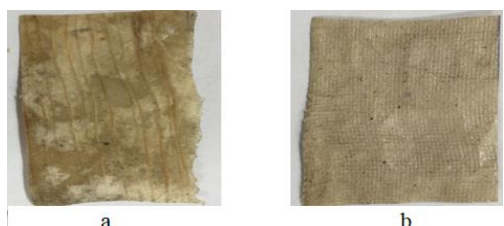

Figure 6: Maize husk-Sisal fibre biocomposite.
Figure 7(a) shows an empty bag, yellowish in colour, which has been manufactured using the maize husk biocomposite. Figure 7(b) shows the bag filled with tomatoes, which attests to its suitability to carry edible food products. 


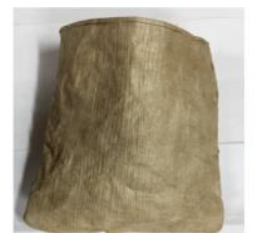

(a)

Figure 7: Bag produced from maize husk fibre biocomposite.

\section{Characterisation of the biodegradable food packaging materials manufactured from agricultural biomass \\ Tear strength}

Tough tear strength is not a common parameter for determining the quality of food packaging materials, but it is important for the design of appropriate food packaging materials (Gupta and Sharma 2010, Ciannamea et al. 2018). In addition, tear strength is crucial for machine performance and in wrapping and sealing operations (Kittur et al. 1998). In this study, the incorporation of sisal fibres in biocomposites was characterised by an increase in tearing strength. The tear strength values of the biocomposites increased with increase in sisal fibre contents, with a significance difference at $\mathrm{p}<0.05$ according to Tukey HSD test, as illustrated in Table 2.

For good quality packaging materials, researchers have reported tear strengths of above 2.0 $\mathrm{MPa}$ which is suitable for food packaging (Briassoulis 2006, Osman et al. 2021). In this study, samples with codes MSFS7 and MFSF8 had tear strengths of 2.56 $\mathrm{MPa}$ and $3.94 \mathrm{MPa}$, respectively. Based on the tear strength results obtained, biocomposites which are suitable for food packaging were developed (codes MFSF7 and MFSF8). Apparently, maize husk fibres can replace other fibres or films used in food packaging manufacturing by up to $50 \%$. Depending on the type of food to be packed, and conditions of storage, materials with lower tearing strength can also be utilized.

\section{Tensile strength}

The tensile strength of the biocomposite increased with increasing proportion of sisal fibres (Table 2). Biocomposites with codes MFSF7 and MFSF8 had tensile strengths of 51.13 and $56.47 \mathrm{MPa}$, respectively. Biocomposites with codes MFSF6, MFSF5, MFSF4, and MFSF3 had tensile strengths of 40.35, 32.97, 29.51, and $19.65 \mathrm{MPa}$, respectively; with significance difference at $p$ $<0.05$ (see Table 2). On the other hand, biocomposites with low amounts of sisal fibres such as MFSF2 and MFSF1 had low tensile strength of 15.50 and $13.35 \mathrm{MPa}$, respectively.

Table 2: Tensile and tear strength of the biocomposites

\begin{tabular}{llll}
\hline Sample code & Ratios maize: sisal & Tensile strength $(\mathrm{MPa})$ & Tear strength $(\mathrm{MPa})$ \\
\hline MFSF1 & $100: 0$ & $13.354 \pm 0.135^{\mathrm{a}}$ & $0.785 \pm 0.015^{\mathrm{a}}$ \\
MFSF2 & $95: 5$ & $15.496 \pm 0.231^{\mathrm{a}}$ & $0.856 \pm 0.004^{\mathrm{b}}$ \\
MFSF3 & $90: 10$ & $19.654 \pm 0.769^{\mathrm{b}}$ & $0.909 \pm 0.008^{\mathrm{c}}$ \\
MFSF4 & $80: 20$ & $29.509 \pm 0.355^{\mathrm{c}}$ & $1.328 \pm 0.004^{\mathrm{d}}$ \\
MFSF5 & $70: 30$ & $32.968 \pm 0.354^{\mathrm{d}}$ & $1.686 \pm 0.025^{\mathrm{e}}$ \\
MFSF6 & $60: 40$ & $40.349 \pm 1.611^{\mathrm{e}}$ & $1.863 \pm 0.006^{\mathrm{f}}$ \\
MFSF7 & $50: 50$ & $51.134 \pm 0.665^{\mathrm{f}}$ & $2.559 \pm 0.016^{\mathrm{g}}$ \\
MFSF8 & $0: 100$ & $56.465 \pm 0.927^{\mathrm{g}}$ & $3.934 \pm 0.030^{\mathrm{h}}$ \\
\hline
\end{tabular}

Briassoulis and Giannoulis (2018) established an optimum tensile strength value of $24 \mathrm{MPa}$ for biocomposite materials in food packaging.

Different food packaging materials made from different bio-based materials have been reported to have tensile strengths mostly in the range of $30 \mathrm{MPa}$ to $60 \mathrm{MPa}$ (Jacob et al.
2020). Other studies have reported tensile strengths ranging from $14 \mathrm{MPa}$ and $19 \mathrm{MPa}$ for food packaging films (Lee et al. 2020b). Biodegradable food packaging made from different proportions of mixture of chitin and cellulose fibres from bamboo were reported to have tensile strengths ranging from $26 \mathrm{MPa}$ to $105 \mathrm{MPa}$ (Bhat et al. 2013). Hai et al. (2020) 
reported tensile strengths ranging from 3.48 to $53.71 \mathrm{MPa}$ for food packaging materials made by different proportions of sago starch, lignin and palm oil. Others have reported lower values of tensile strengths such as Gurler et al. (2021) who reported a tensile strength of $1.017 \pm 0.35 \mathrm{MPa}$ for food packaging films prepared from biodegradable polymers. The tensile strength of food packaging materials made from chitosan films and methyl cellulose were reported to have tensile strengths of $14.6 \pm 35.1 \mathrm{MPa}$ and 43.7 $\pm 70.2 \mathrm{MPa}$, respectively (Butler et al. 1996, Kittur et al. 1998).

A review by Kuorwel et al. (2015) showed the tensile strength of most food packaging materials ranged from 2.2 MPa to 88.9 MPa. The extant literature reveals that the higher the tensile strength, the better the materials for food packaging. Comparing the results from this study and those from extant literature, the biocomposite manufactured from $80 \%$ of maize cornhusk had enough tensile strength for food packaging. Moreover, the minimum tensile strength required for food packaging materials could depend on the type of food being packed, and storage conditions. Depending on type of food and method of storage, it is possible to utilise $100 \%$ maize husk fibres.

\section{Abrasion resistance}

Abrasion resistance of food packaging materials helps to characterise the abrasive deformation of materials imposed by the packaged food. Food packaging helps to resist wear to prevent contamination. These materials have been reported to have a mass loss of about $0.37 \%$ after 1000 cycles (Wang et al. 2013). Abrasion results from different samples of biocomposites developed in this study, using maize and sisal fibres, were observed after every 5,000 cycles to assess mass loss. The tests verified that no mass loss was observed at 5,000, 10,000 and 15,000 cycles primarily due to the presence of shorter cellulose fibres on the surface of the biocomposites, which reduces the wear of materials (Gurunathan et al. 2015). The abrasion resistance of the biocomposites developed in this study was fairly good relative to other food packaging materials reported in other studies (Marsh and Bugusu 2007, Wang 2013, Gurunathan et al. 2015).

\section{Conclusion}

This research project successfully developed a biodegradable food packaging material based on cellulosic fibres (maize husk and sisal) and cellulose pulp (maize husk). The results showed that the biocomposite has reasonably flexible properties with decent appearance and smooth surface, which makes it suitable as food packaging material.

The study findings support the following conclusions: Firstly, the study has established optimum extraction conditions for maize husk fibres at $5 \mathrm{~g} / \mathrm{l}$ of $\mathrm{NaOH}, 100{ }^{\circ} \mathrm{C}$ for 60 minutes and liquor ratio of 1:20. Secondly, it has established the optimum conditions for preparing a cellulose biocomposite at $24 \mathrm{ml}$ maize husk pulp and ratio of 50:50 (sisal fibres and maize husk fibres). Also, a packaging material has been developed from maize husk and sisal fibres, which can potentially replace non-renewable resources used in food packaging industries. The results from mechanical testing indicate that the mechanical properties of the biocomposite materials were related to the composition of the types of fibres used. Tear and tensile strength increased with the rising proportions of sisal fibres in the biocomposite material. The tensile and tearing strengths of the biocomposite were found to be within the range of values reported by other researchers. Furthermore, the study observed that the biocomposite material achieved good abrasion resistance that can permit its usability in food packaging without necessarily losing its properties.

\section{Acknowledgements}

This work was carried out with aid from the University of Dar es Salaam stemming from successful acquisition of competitive research funding during the 2019-2020 academic year (Project No: CoAFFST20039).

Conflict of Interest: The authors declare no conflict of interest. 


\section{References}

Accinelli C, Accinelli C, Saccà ML, Mencarelli M and Vicari A 2012 Deterioration of bioplastic carrier bags in the environment and assessment of a new recycling alternative. Chemosphere 89(2): 136-143.

Butler B, Vergano PJ, Testin RF, Bunn JM and Wiles JL 1996 Mechanical and barrier properties of edible chitosan films as affected by composition and storage. $J$. Food Sci. 61(5): 953-956.

Bhardwaj T, A, Alam T, Sharma V, Alam MS, Hamid H and Deshwal GK 2020 Lignocellulosic agricultural biomass as a biodegradable and eco-friendly alternative for polymer-based food packaging. $J$. Pack. Technol. Res. 4(2): 205-216.

Bhat H, Dasan Y, Khan I and Jawaid M 2017 Cellulosic biocomposites: Potential materials for future. In: Jawaid M, Salit M, Alothman O (Eds) Green Biocompos. (pp 69-100), Springer, Cham.

Briassoulis D 2006 Mechanical behaviour of biodegradable agricultural films under real field conditions. Polymer Degrad. Stabil. 91(6): 1256-1272.

Briassoulis D and Giannoulis A 2018 Evaluation of the functionality of biobased food packaging films Polymer Testing 69: 39-51.

Chander M 2019 Microbial production of biodegradable plastics from agricultural waste. Int. J. Res. Anal. Rev. 3: 593-602.

Ciannamea EM, Castillo LA, Barbosa SE and De Angelis MG 2018 Barrier properties and mechanical strength of bio-renewable, heat-sealable films based on gelatin, glycerol and soybean oil for sustainable food packaging. React. Funct. Polym. 125: 29-36.

Dungani R, Karina M, Sulaeman A, Hermawan D and Hadiyane A 2016 Agricultural waste fibers towards sustainability and advanced utilization: Asian J. Plant Sci. 15: 42-55.

Ebisike K, AttahDaniel BE, Babatope B and Olusunle SOO 2013 Studies on the extraction of naturally-occurring banana fibers. Int. J. Eng. Sci. 2(9): 95-99.

Folino A, Karageorgiou A, Calabrò PS and
Komilis D 2020 Biodegradation of wasted bioplastics in natural and industrial environments: A review. Sustainability 12(15): 6030.

Franz R, and Welle F 2003 Recycling packaging materials. In: Novel Food Packaging Techniques 497-518.

Genco G, Lo Monaco A, Pelosi C, Picchio R and Santamaria UP 2011 Study of colour change due to accelerated sunlight exposure in consolidated wood samples. Wood Res. 56(4): 511-524.

Gürler N, Paşa S, Temel H 2021 Silane doped biodegradable starch-PLA bilayer films for food packaging applications: Mechanical, thermal, barrier and biodegradability properties. J. Taiwan Inst. Chem. Eng. 123, 261-271.

Gurunathan T, Mohanty S and Nayak SK 2015 A review of the recent developments in biocomposites based on natural fibres and their application perspectives. Composites Part A: Appl. Sci. Manufact. 77: 1-25.

Gupta A and Sharma M 2010 Characterization of biodegradable packaging films derived from potato starch and LDPE grafted with maleic anhydride-LDPE composition. Part-Ii. J. Polym. Environ. 18(4): 492-499.

Hai L, Choi ES, Zhai L, Panicker PS and Kim J 2020 Green nanocomposite made with chitin and bamboo nano fibers and its mechanical, thermal and biodegradable properties for food packaging. Int. J. Biol. Macromol. 144: 491-499.

Halonen N, Pálvölgyi PS, Bassani A, Fiorentini C, Nair R, Spigno $G$ and Kordas K 2020 Bio-based smart materials for food packaging and sensors-A review. Front. Mater. 7: 82.

Huq T, Salmieri S, Khan A, Khan RA, Le Tien C, Riedl B, Fraschini C, Bouchard J, Uribe-Calderon J, Kamal MR and Lacroix M 2012 Nanocrystalline cellulose (NCC) reinforced alginate based biodegradable nanocomposite film. Carbohydr. Polym. 90(4): 1757-1763.

Ibrahim MS, Sani N, Adamu M and Abubakar MK 2018 Biodegradable polymers for sustainable environmental 
and economic development. MOJ Biorg. Org. Chem. 2: 192-194.

Jacob J, Lawal U, Thomas S and Valapa RB 2020 Biobased polymer composite from poly (lactic acid): processing, fabrication, and characterization for food packaging. In Processing and Development of Polysaccharide-Based Biopolymers for Packaging Applications (pp. 97-115). Elsevier.

Jain A, Rastogi D, Chanana B, Parmar MS and Dhama A 2017 Extraction of cornhusk fibres for textile usages. $J$. Polym. Textile Eng. 4(1): 29-34.

Johansson C, Bras J, Mondragon I, Nechita P, Plackett D, Simon P, Svetec DG, Virtanen S, Baschetti MG, Breen C and Aucejo S 2012 Renewable fibers and bio-based materials for packaging applications-A review of recent developments. BioResources 7: 2506-2552.

Kambli N, Basak S, Samanta KK and Deshmukh RR 2016 Extraction of natural cellulosic fibers from cornhusk and its physico-chemical properties. Fibers Polym. 17(5): 687-694.

Kittur F, Kumar KR and Tharanathan RN 1998 Functional packaging properties of chitosan films. Zeitsch. Lebensmitteluntersuch. Forsch. A 206: 4447.

Koch D and Mihalyi B 2018 Assessing the change in environmental impact categories when replacing conventional plastic with bioplastic in chosen application fields. Chem. Eng. Trans. 70: 853-858.

Kuorwel K, Cran MJ, Orbell JD, Buddhadasa S and Bigger SW 2015 Review of mechanical properties, migration, and potential applications in active food packaging systems containing nanoclays and nanosilver. Compr. Rev. Food Sci. Food Safety 14(4): 411-430.

Klemm D, Schumann D, Kramer F, Heßler N, Koth D and Sultanova B 2009 Nanocellulose materials-different cellulose, different functionality. In Macromolecular Symposia (Vol. 280, No. 1, Pp. 60-71). Weinheim: Wiley-VCH Verlag.
Lavanya D, Kulkarni PK, Dixit M, Raavi PK and Krishna LNV 2011 Sources of cellulose and their applications-a review. Int. J. Drug Form. Res. 2(6): 19-38.

Lee C, Khalina A, Lee S and Liu M 2020a A Comprehensive review on bast fibre retting process for optimal performance in fibre-reinforced polymer composites. $A d v$. Mater. Sci. Eng. 2020: 27.

Lee H, Cho CH, Kim HK and Yoo S 2020b Improved physical and mechanical properties of food packaging films containing calcium hydroxide as a $\mathrm{CO}_{2}$ adsorbent by stearic acid addition. Food Package Shelf Life 26: 100558.

Li H, Zhou J, Zhang J, Sun G, Yang Y and Liang F 2013 The optimum delignification conditions and delignification course during the pretreatment process of poplar kraft pluping with green liquor pretreatment. Int. Conf. Mater. Renew. Energy Environ. 1: 345-50, IEEE.

Maity S, Singha K, Gon DP, Paul P and Singha M 2012 A review on jute nonwovens manufacturing, properties and applications. Int. J. Textile Sci. 1(5): 3643.

Makhijani K, Kumar R and Sharma SK 2015 Biodegradability of blended polymers: A comparison of various properties. Crit. Rev. Environ. Sci. Technol. 45(16): 18011825.

Marichelvam M, Jawaid $\mathrm{M}$ and Asim M 2019. Corn and rice starch-based bioplastics as alternative packaging materials. Fibers 7(4): 32.

Marsh K and Bugusu B 2007 Food packaging-role, materials and environmental issues. J. Food Sci. 72(3): 39-55.

Mooney P 2009 The second green revolution? Production of plant-based biodegradable plastics. Biochem. J. 418(2): 219-232.

Mostafa N, Farag AA, Abo-dief HM and Tayeb AM 2018 Production of biodegradable plastic from agricultural wastes. Arabian J. Chem. 11(4): 546-553.

Opara U, and Mditshwa A 2013 A review on the role of packaging in securing food system: adding value to food products and reducing losses and waste. African 
Journal of Agricultural Research. 8(22): 2621-2630.

Osman AF, Siah L, Alrashdi AA, Ul-Hamid $A$ and Ibrahim I 2021 Improving the tensile and tear properties of thermoplastic starch/dolomite biocomposite film through sonication process. Polymers 13(2): 274.

Reddy N and Yang Y 2005 Properties and potential applications of natural cellulose fibers from cornhusks. Green Chemistry 7(4): 190-195.

Samir A, Alloin F and Dufresne A 2005 Review of Recent Research into cellulosic whiskers, their properties and their application in nanocomposite field. Biomacromolecules 6(2): 612-626.

Salam A, Reddy N and Yang Y 2007 Bleaching of kenaf and cornhusk fibers. Industr. Eng. Chem. Res. 46(5): 14521458.

Vardhini K, Murugan R, Selvi C and Surjit R 2016 Optimisation of alkali treatment of banana fibres on lignin removal. Indian J. Fibre Textile Res. 41(2): 156-160.

Wang J, Zhu Y and Fu F 2013 Abrasion resistance of biaxially oriented polypropylene films coated with nanocomposite hard coatings. Appl. Surface Sci. 285: 697-701.

Wohner B, Pauer E, Heinrich V and Tacker M 2019 Packaging-related food losses and waste: an overview of drivers and issues. Sustainability 11(1): 264.

Wulandari W, Rochliadi A, and Arcana I 2016 Nanocellulose prepared by acid hydrolysis of isolated cellulose from sugarcane bagasse. IOP Conference series: Mater. Sci. Engin. 107(1): 012045.

Yang J, Ching YC and Chuah CH 2019 Applications of lignocellulosic fibers and lignin in bioplastics: a review. Polymers 11(5): 751.

Yilmaz N 2013 Effect of chemical extraction parameters on corn husk fibres characteristics. Indian J. Fibre Textile Res. 38: 29-34.

Zikmanis P, Kolesovs $\mathrm{S}$ and Semjonovs $\mathrm{P}$ 2020 Production of biodegradable microbial polymers from whey. Bioresour. Bioprocess. 7: 36. 